\title{
Combined global climate model and mesoscale model simulations of Antarctic climate
}

\author{
Keith M. Hines, David H. Bromwich, 1 and Zhong Liu \\ Polar Meteorology Group, Byrd Polar Research Center, Ohio State University, Columbus
}

\begin{abstract}
Simulations of high southern latitudes with the high-resolution, limited-area Penn State/NCAR mesoscale model, version 4 (MM4), examine the impact of a moist physics parameterization and the success of a one-way nesting inside the global NCAR community climate model, version 2 (CCM2). Discretization is by $100 \mathrm{~km}$ resolution in the horizontal and 15 or 16 levels in the vertical. Initial and boundary conditions for the simulations are provided by analyses of the European Centre for Medium-Range Weather Forecasts or CCM2 simulations. Comparisons of dry and moist simulations of an austral winter month, June 1988, are used to examine the role of clouds in the regional meteorology. A cloud-free MM4 simulation with boundary conditions provided by CCM2 run 422 indicates that the one-way nesting of the mesoscale model can produce significant differences in the model output, including an improvement in the location of one longwave trough, reduced cold bias, and a more detailed surface wind field. The improved location of the longwave trough over the Atlantic Ocean is hypothesized to result from blocking induced by the reduced cold bias. The nested simulation is sensitive to the forcing at the horizontal boundaries. Consequently, proper location of troughs and ridges at the boundaries is required for the model to well represent all the major troughs and ridges inside the domain. The addition of moist physics to the mesoscale simulations tends to improve the quality of the simulated fields over the Southern Ocean. In particular, the intensity of the circumpolar trough is increased. Over Antarctica, serious deficiencies are found in the simulations with moist physics. Excessive moisture is apparently stored in the simulated clouds leading to excessive atmospheric back radiation and, consequently, excessive temperatures at the surface and higher up in the troposphere.
\end{abstract}

\section{Introduction}

Despite the many fascinating aspects of Antarctica's climate, previous regional modeling studies [e.g., Parish and Bromwich, 1991; Parish, 1992] have generally been limited to idealized scenarios until very recently. Thus realistic simulations of high southern latitude climate which consider such components as diurnal and seasonal cycles, precipitation, longwave and shortwave radiation, and planetary boundary layer (PBL) effects could only be performed by global climate models (GCMs) that have a relatively coarse resolution of the regional climate forcings. Yet, mesoscale processes play a critical role in the Antarctic regional climate. Regional modeling studies are now beginning to detail features of the Antarctic climate with a high resolution of the critical topographic forcing [e.g., Gallée and Schayes, 1994; Gallée, 1995; Walsh and McGregor, 1996]. Many of the physical parameterizations included within current numerical models have not been sufficiently tested for polar climates. A major effort, the Surface Heat Budget of the Arctic (SHEBA) [Moritz et al., 1993] project, is under way in high northern latitudes to

\footnotetext{
1Also at Atmospheric Sciences Program, The Ohio State University, Columbus.
}

Copyright 1997 by the American Geophysical Union.

Paper number 97JD00792.

0148-0227/97/97JD-00792\$09.00 obtain the observations necessary to test and develop physical parameterizations for that region. Efforts are also required to test parameterizations in high southern latitudes which are colder, on the average, than high northern latitudes and also heavily influenced by the huge Antarctic ice sheet. Approximately $70 \%$ of the Antarctic surface is above $2000 \mathrm{~m}$. The sloping ice terrain combines with intense radiative cooling to produce the highly persistent katabatic winds along the coastal ice slopes which have annual average wind speeds of up to $19.7 \mathrm{~m} \mathrm{~s}^{-1}$ (at Cape Denison [Mather and Miller, 1967]).

As more powerful supercomputers have become available, the horizontal resolution in GCM studies has increased. The current generation of higher-resolution GCMs [e.g., Tzeng $\boldsymbol{e t}$ al., 1994; Chen et al., 1995] produce a significantly improved simulation of the high southern latitude climate over that by lower-resolution GCMs [Xu et al., 1990] of the previous decade. Tzeng et al. [1994] find that the National Center for Atmospheric Research (NCAR) community climate model, version 2 (CCM2) [Hack et al., 1993], with a horizontal resolution of $\mathrm{T} 42$ (approximately $2.8^{\circ}$ latitude $\times 2.8^{\circ}$ longitude) simulates a more realistic Antarctic climate than its predecessor CCM1, with a horizontal resolution of R15 (approximately $4.5^{\circ}$ latitude $\times 7.5^{\circ}$ longitude). Some of the features that CCM2 simulates well are the coreless winter over the high interior plateau, the distribution and intensity of the inversion, and the arid climate. Improvements in simulated climate can be achieved by nesting a highresolution mesoscale model within a GCM. The nested model 
technique can significantly improve the simulation of precipitation over complex terrain [e.g., Giorgi and Bates, 1989; Pitman et al., 1991; Giorgi et al., 1994]. Concerning the polar regions, Lynch et al. [1995] recently performed a nested modeling study of the western Arctic sector. In this paper, we shall use a nested mesoscale model to study the climate near Antarctica.

This research is a continuation of regional modeling studies of high southern latitude climate begun by Hines et al. [1995, hereinafter referred to as HBP]. They evaluate the performance of a modified version of the Pennsylvania State University (PSU)/NCAR mesoscale model, version 4 (MM4). This cloud-free version of the mesoscale model produces a quite reasonable representation of the persistent katabatic winds over Antarctica. In a simulation of June 1988 with initial and boundary conditions adapted from analyses by the European Centre for Medium-Range Weather Forecasts (ECMWF), they find that MM4 produces many timeaveraged features seen in the ECMWF analyses, including major lows at the surface near $0^{\circ}$ and $80^{\circ} \mathrm{E}$ and at $500 \mathrm{hPa}$ near $15^{\circ} \mathrm{W}, 60^{\circ} \mathrm{E}$, and $160^{\circ} \mathrm{W}$. The difference between the $500 \mathrm{hPa}$ height fields of the mesoscale model and the analyses does not exceed about $50 \mathrm{~m}$ throughout the domain. The intensity of the circumpolar trough and the lows in the surface pressure field is underestimated in the simulations of HBP. This was attributed to weaker cyclogenesis resulting from the lack of latent heating. They also compared the results of the month-long simulation with boundary layer observations at nine automatic weather stations (AWS) [Stearns et al., 1993]. Simulated temperature and velocity agree quite well with that of the AWS observations. For the present study, we use the high-resolution mesoscale model of HBP. The model, modified to include moist atmospheric processes including latent heating, cloud-radiation effects and precipitation, can be run independently with initial and boundary conditions obtained from analyses by ECMWF or be nested one way within the NCAR CCM2. In HBP the focus was an assessment of cloud-free simulations. The present study evaluates the simulated climate both when MM4 is nested inside CCM2 and when the moist physics parameterization is included.

\section{Model Description}

Anthes et al. [1987] describe in detail the high-resolution MM4, a three-dimensional, hydrostatic, primitive-equation model. Here, we provide a brief summary of the version of MM4 which has been modified for ice-sheet meteorology by HBP. The prognostic variables include surface pressure, temperature, and horizontal velocity. Key parameterizations for the simulation of katabatic winds include those of the PBL and longwave radiation. The cloud physics parameterization is the explicit moisture scheme [Hsie and Anthes, 1984] modified for treatment of ice/snow at temperatures below 273.15 K [Dudhia, 1989]. A similar moist physics scheme is employed by Gallée [1995] in his simulation of mesocyclones over the Ross Sea. The explicit moisture scheme includes prognostic equations for the local mass fraction of water vapor, cloud, and precipitation. Rain and snow fall out of the atmosphere at a calculated terminal velocity. The merits of the explicit moisture scheme for high southern latitudes are examined by Hines et al. [1997]. In this paper, we will limit our analysis to the scheme's effect on the numerical simulations.
The PBL representation is based upon the high vertical resolution approach of Zhang and Anthes [1982] which includes four regimes for different ranges of static stability. Surface roughness is set at $0.01 \mathrm{~m}$ over the Antarctic continent and $0.001 \mathrm{~m}$ over pack ice and the permanent ice shelves. Surface roughness over the open oceans increases as the boundary layer wind speed increases. Minimum roughness over the oceans is $0.0001 \mathrm{~m}$. The diffusion of temperature is adjusted to conserve the turbulent flux of heat in the vertical. For stable stratification, sensible heat flux and vertical diffusivities within the lowest $2000 \mathrm{~m}$ above ground level (AGL) are obtained from the profile equation of Brost and Wyngaard [1978]. Furthermore, to reduce the downward flow of heat within the inversion in the lower atmosphere, minimum diffusivity is reduced from the standard MM4 value of $1.0 \mathrm{~m}^{2} \mathrm{~s}^{-1}$ to $0.1 \mathrm{~m}^{2} \mathrm{~s}^{-1}$ in the lowest $1000 \mathrm{~m}$ AGL. Above $1 \mathrm{~km}$, minimum diffusivity increases linearly with height to $1.0 \mathrm{~m}^{2} \mathrm{~s}^{-1}$ at $2 \mathrm{~km}$ AGL. For unstable stratification or above $2 \mathrm{~km} \mathrm{AGL}$, diffusivity is obtained following Zhang and Anthes [1982]. The surface temperature $T_{g}$ is obtained from the surface energy balance,

$$
\frac{\partial T_{g}}{\partial t}=\frac{R_{a}-R_{g}-H_{s}-E L_{v}+S_{g}}{C_{g}}-K_{m}\left(T_{g}-T_{m}\right)
$$

where $t$ is time, $R_{a}$ and $R_{g}$ are downward and upward longwave radiative fluxes from the atmosphere and the surface, respectively, $H_{s}$ is sensible heat flux from the surface to the atmosphere, $E$ is evaporation or sublimation, $L_{v}$ is latent heat of vaporization or sublimation, $S_{g}$ is the absorbed shortwave radiation, $T_{m}$ is substrate temperature, $C_{g}$ is thermal capacity per unit area of the surface, and $K_{m}$ is the heat transfer coefficient of the force restore method. On the basis of Parish and Waight [1987], $K_{m}$ is set at $1.82 \times 10^{-5} \mathrm{~s}^{-1}$. For the Antarctic ice surface, $C_{g}$ is $1.649 \times 10^{5} \mathrm{~J} \mathrm{~m}^{-2} \mathrm{~K}^{-1}$. For the unstable boundary layer, $H_{s}$ is obtained following Zhang and Anthes [1982]. Sea ice concentration is specified over the oceans. For pack ice grid points, separate values of $T_{g}, T_{m}, H_{s}, E, R_{g}$, and $S_{g}$ are retained for the ice and water surface fractions. The temperature of the water surface fraction is $271.4 \mathrm{~K}$, which is taken as the freezing point of seawater. $T_{g}$ and $T_{m}$ of the ice surface fraction are constrained to be less than or equal to $271.4 \mathrm{~K}$.

The mesoscale model includes a choice of two radiation schemes. For dry simulations, we use the clear sky, gray body scheme of Cerni and Parish [1984], which has been shown to produce realistic katabatic winds in simulations of the flow in the vicinity of West Antarctica [Bromwich et al., 1994]. Moist simulations use a radiation scheme adapted for mesoscale models from CCM1 [Williamson et al., 1987] and obtained from the Pacific Northwest Laboratory.

The horizontal domain of the simulation is a $7900 \times 7900$ $\mathrm{km}$ polar stereographic grid centered at the south pole (Figure 1a). Horizontal resolution is $100 \mathrm{~km}$. Vertical discretization is by the terrain-following $\sigma$ coordinate, with 15 and 16 levels for the dry and moist versions, respectively, of the model. The lowest atmospheric temperature and horizontal velocity are approximately $23 \mathrm{~m}$ above the surface. The model top is at 100 and $10 \mathrm{hPa}$, respectively, for the dry and moist versions.

Climatological monthly sea ice and sea surface temperature distributions are obtained from the Geophysical Fluid Dynamics Laboratory (GFDL) global oceanographic data set atlas. At pack ice grid points, the model considers two surface 


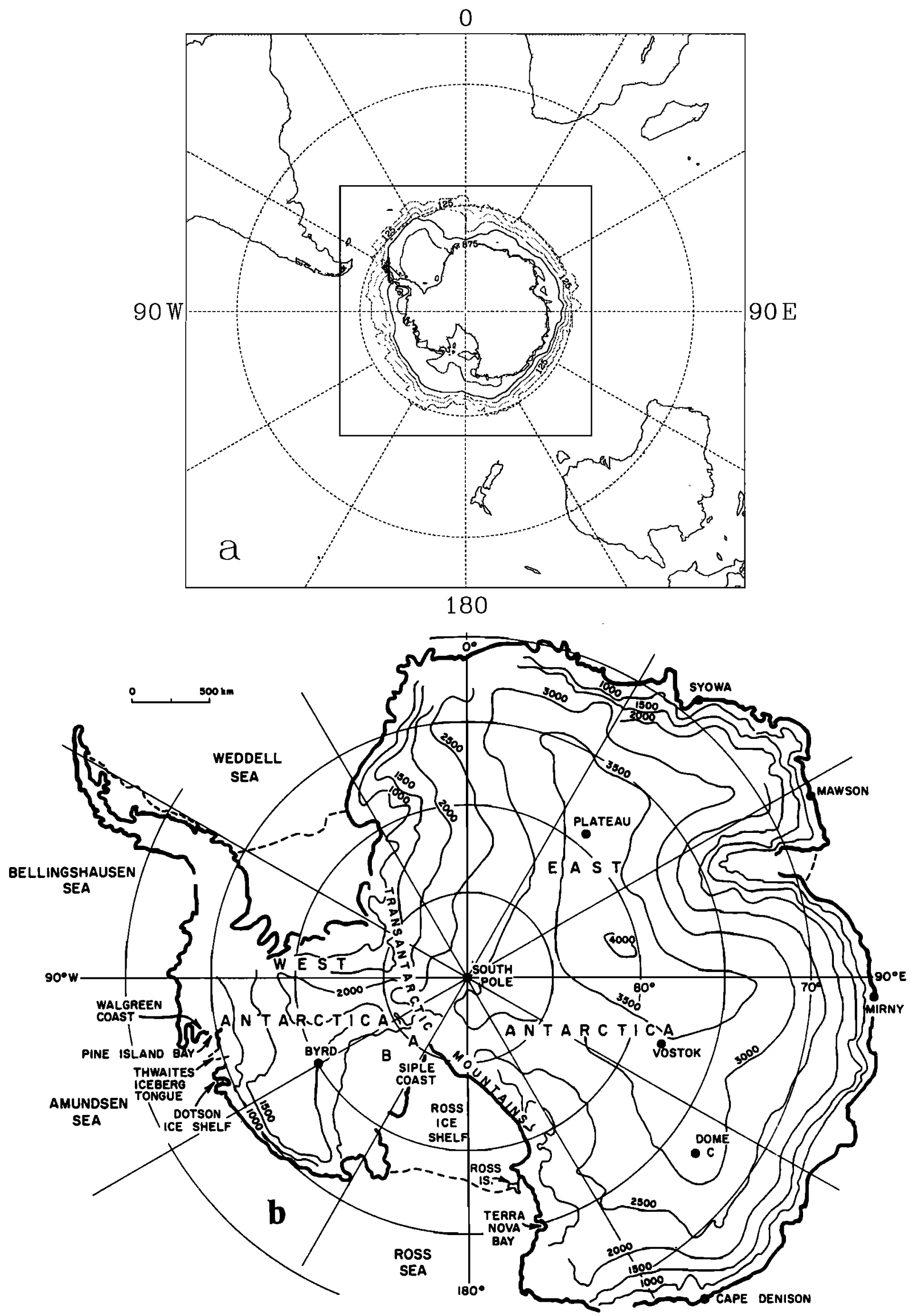

Figure 1. Area maps showing (a) $7900 \mathrm{~km} \mathrm{x} 7900 \mathrm{~km}$ grid with sea ice concentration denoted by contours; contour interval is 0.25; and (b) geographic features of high southern latitudes [adapted from Hines et al., 1995]. 

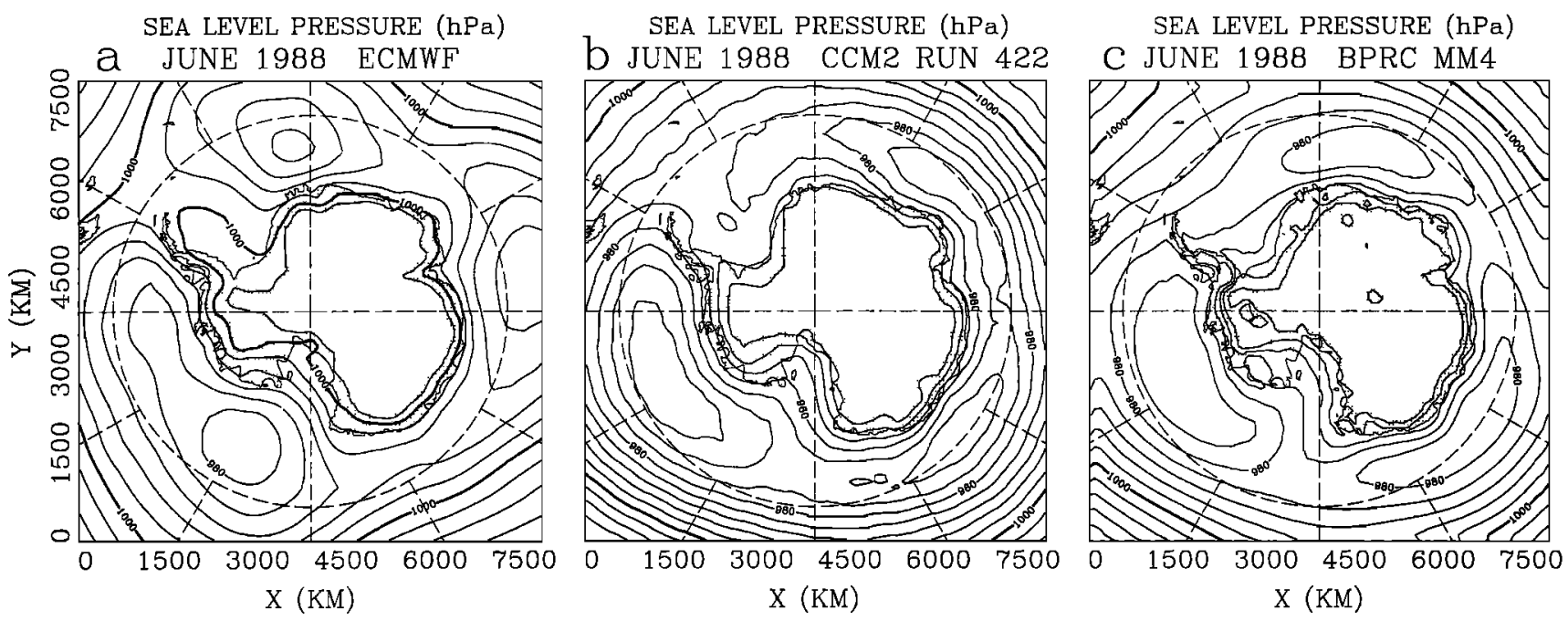

Figure 2. Sea level pressure (hectopascals) averaged over June 1988 for (a) the European Centre for Medium-Range Weather Forecasts (ECMWF) analyses, (b) community climate model, version 2 (CCM2) run 422, and (c) the dry mesoscale model, version 4 (MM4) simulation with CCM2 boundary conditions. Contour interval is $4 \mathrm{hPa}$. Thick contour is $1000 \mathrm{hPa}$. Contours are suppressed over high terrain.

temperatures, one for the ice-covered fraction and one for the water surface fraction. Substrate temperatures and the initial surface temperatures over the Antarctic ice surface are obtained from the ECMWF/Tropical Ocean Global Atmosphere (TOGA) data set. Surface height data are adapted from Drewry [1983]. Figure lb shows geographic features of interest for Antarctica.

Initial conditions and time-varying boundary conditions are interpolated from either of two sources: analyses by ECMWF or output of CCM2 simulations. Simulations presented in this paper cover the period from 0000 coordinated universal time (UTC) June 1 to 0000 UTC July 1, 1988.

\section{Results}

\subsection{MM4 Dry Simulation With Initial and Boundary Conditions From CCM2 Results}

We begin by examining the one-way nesting of the dry version of the mesoscale model inside CCM2. The global model's results provide time-varying boundary conditions for the limited-area domain. The mesoscale model has no impact, however, on the CCM2 simulation. The intent is to improve the simulation of high southern latitudes by utilizing a significantly better resolution of regional meteorological forcings. The simulation of high southern latitude climate by CCM2 with a horizontal resolution of T42 is much improved over that of CCM1 with a lower horizontal resolution of R15 [Tzeng et al., 1993, 1994]. The positive moisture fixer scheme in CCM1 results in excessive precipitation and cloudiness over Antarctica [Tzeng et al., 1993]. In contrast, CCM2's semi-Lagrangian moisture transport and improved horizontal resolution greatly improve the simulation of Antarctic precipitation. Bromwich et al. [1995a] note that south of $70^{\circ} \mathrm{S}, \mathrm{CCM} 2 \mathrm{~s}$ area-averaged annual precipitation, $21.6 \mathrm{~cm}$, is very close to Peixoto and Oort's [1992] estimated value, 19.0 $\mathrm{cm}$. Tzeng et al. [1994] find that the circumpolar trough, seen in the sea level pressure field surrounding Antarctica, is well located by CCM2, but the intensity is too strong (Figure 2). Furthermore, the major trough locations for the latitude band near the circumpolar trough are displaced to the east by $15^{\circ}$ to $40^{\circ}$ longitude from climatological positions (Figures 2 and 3 ).
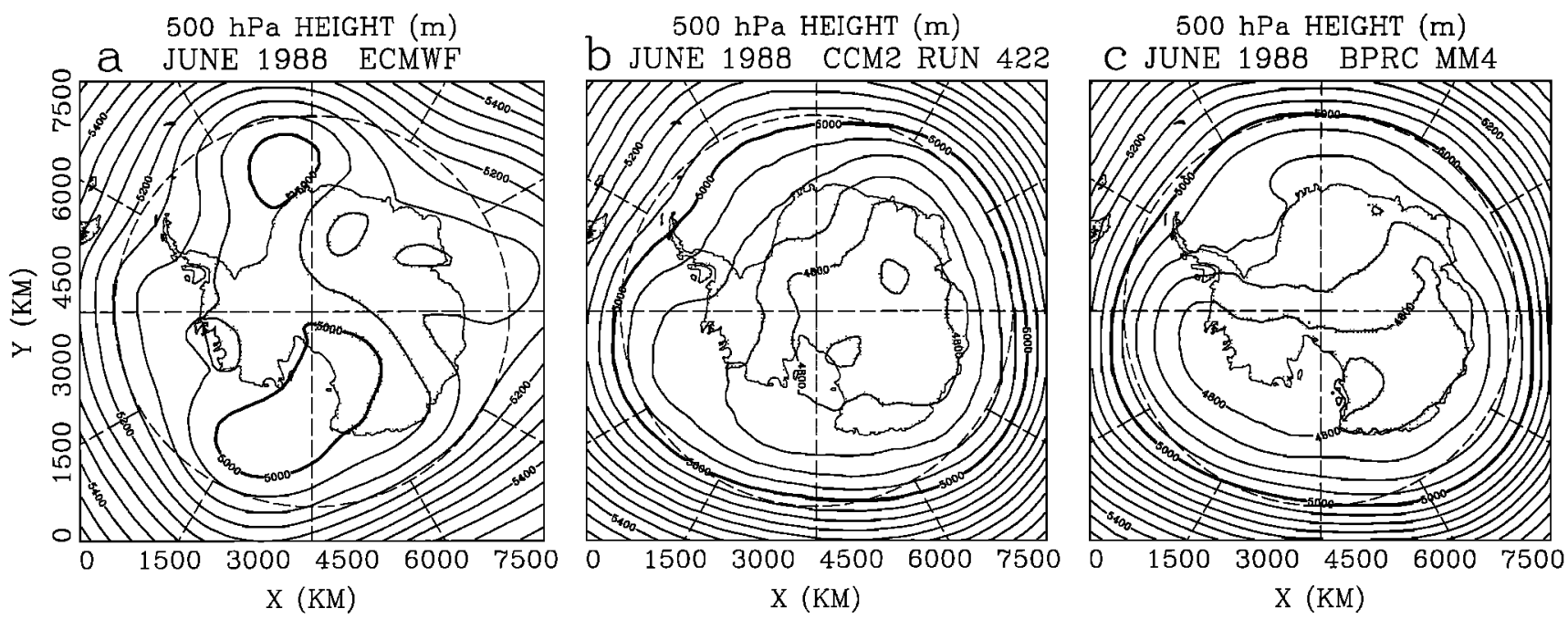

Figure 3. Same as Figure 2 except for geopotential height (geopotential meters) at $500 \mathrm{hPa}$. Contour interval is $50 \mathrm{gpm}$. Thick contour is $5000 \mathrm{gpm}$. 
They note that the intensity and horizontal distribution of the surface inversion are well captured by CCM2, although the inversion strength may be slightly larger than values analyzed by Phillpot and Zillman [1970]. The specification of uniform $2 \mathrm{~m}$ thick sea ice by CCM2 contributes to the cold bias of the surface air temperature in high southern latitudes.

We choose to nest the mesoscale model for a selected month within CCM2 run 422 [Williamson, 1993], a multiyear simulation including the 1979-1988 period of the Atmospheric Model Intercomparison Project [Gates, 1992]. The boundary conditions of run 422 include observed sea ice and sea surface temperature distributions. The nesting is one way with $\mathrm{CCM} 2$ providing the initial conditions and timevarying boundary conditions for the MM4 simulation of June 1988. The same winter mionth was simulated by HBP with ECMWF boundary conditions. Figure 3 shows the timeaveraged $500 \mathrm{hPa}$ height fields in geopotential meters (gpm) for the ECMWF analyses, the CCM2 results, and the MM4 results over the latter's domain. Significant differences are seen between the results of the GCM in Figure $3 \mathrm{~b}$ and the mesoscale model in Figure 3c. Over the high interior plateau the mesoscale simulation produces higher heights, by up to $120 \mathrm{~m}$, than that of the CCM2 simulation. The result is a vortex over the plateau which more closely resembles that of the ECMWF analyses. Tzeng et al. [1994] have noted that CCM2 simulates climatological troughs that are significantly displaced from their observed position. This is clearly seen by comparing Figures $3 a$ and $3 b$. Two of the troughs are similarly displaced in the mesoscale simulation (Figure 3c). The trough near $5^{\circ} \mathrm{W}$, however, is near the observed climatological position. Thus the mesoscale model does produce significant improvements in the simulation of high southern latitude climate.

Differences between CCM2 and MM4 results at the surface are seen in Figure 2, which displays the sea level pressure field, averaged over the month. The differences in pressure gradient between Figures $2 b$ and $2 c$ indicate that important changes in the boundary layer velocity field result from the nesting. In the CCM2 simulation the low-level geostrophic wind field includes northerly flow west of the Antarctic Peninsula and easterly flow along the coast of West Antarctica. This pattern is much weaker in the mesoscale simulation. The sea level pressure within the circumpolar trough and the surface lows tends to be lower in the CCM2 simulation. The pressure difference between the models averages about $6 \mathrm{hPa}$ at $65^{\circ} \mathrm{S}$. Apparently, the tendency of CCM2 to oversimulate the intensity of the trough [Tzeng et al., 1994] has been offset by the mesoscale model's tendency to undersimulate the intensity of the trough (HBP). Thus the intensity of the circumpolar trough simulated by MM4 is close to that of the observed field.

Over Antarctica the simulation of relatively low heights at $500 \mathrm{hPa}$ by CCM2 (Figure $3 \mathrm{~b}$ ) would seem to be consistent with the cold central core in the $500 \mathrm{hPa}$ temperature field (Figure 4b). The mesoscale model, on the other hand, simulates temperatures over Antarctica comparable with those of the ECMWF analyses (Figures $4 a$ and $4 c$ ). Over the Southern Ocean near Antarctica the simulation of lower than observed middle-tropospheric temperatures by HBP was attributed to the absence of latent heating in the cloud-free model. Similarly, at $500 \mathrm{hPa}$ the same model produces slightly colder offshore temperatures than CCM2 does.

Figure 5 shows the surface temperature field for the two models. The results provide more evidence that nesting a mesoscale model within a GCM can produce significant differences in the simulated fields. In the CCM2 simulation, temperature is extremely cold over the high plateau of East Antarctica with a minimum of $188 \mathrm{~K}$. In the mesoscale simulation, minimum surface temperature is about $10 \mathrm{~K}$ warmer, and the intensity of the strong surface inversion (not shown) is slightly weaker, than that of the GCM simulation. It will be seen later that these differences may be important for the development of blocking over Antarctica and the location of climatological troughs.

In the CCM2 results, a cold tongue extends from the high plateau located west of the Ross Ice Shelf to north of the Ross Sea. The cold tongue can result from the extremely cold air draining off the plateau. Surface temperature is relatively warm over the eastern Ross Ice Shelf in Figure 5a. Off the coast of West Antarctica the surface temperature tends to be warmer in the CCM2 simulation than in the MM4 simulation. The time-averaged low-level wind field in the former simulation (Figure 6a) suggests that warm advection by northerly winds between $75^{\circ} \mathrm{W}$ and $60^{\circ} \mathrm{W}$ is responsible for the temperature difference. The differences in the low-level wind field between the models seen in Figure 6 also
500 hPa TEMPERATURE (K)

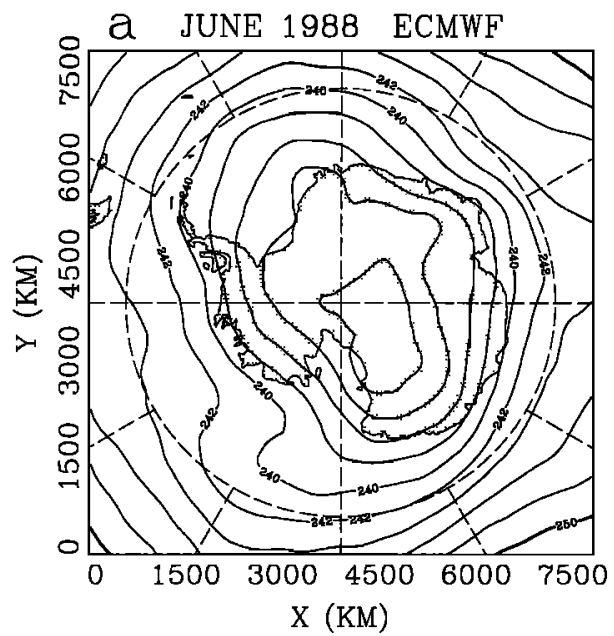

$500 \mathrm{hPa}$ TEMPERATURE (K)
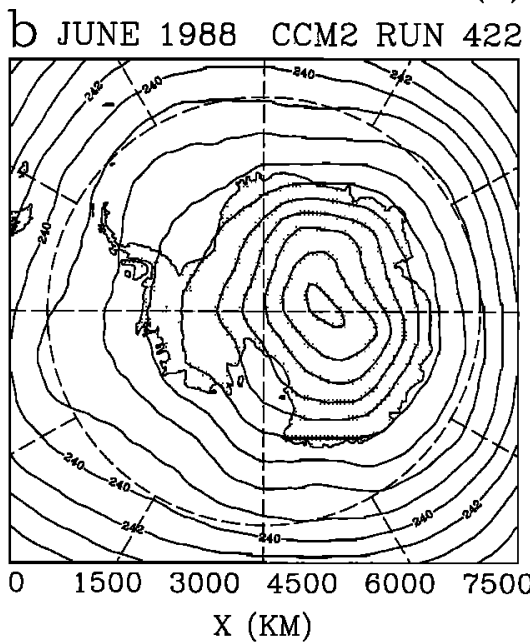

$500 \mathrm{hPa}$ TEMPERATURE (K)
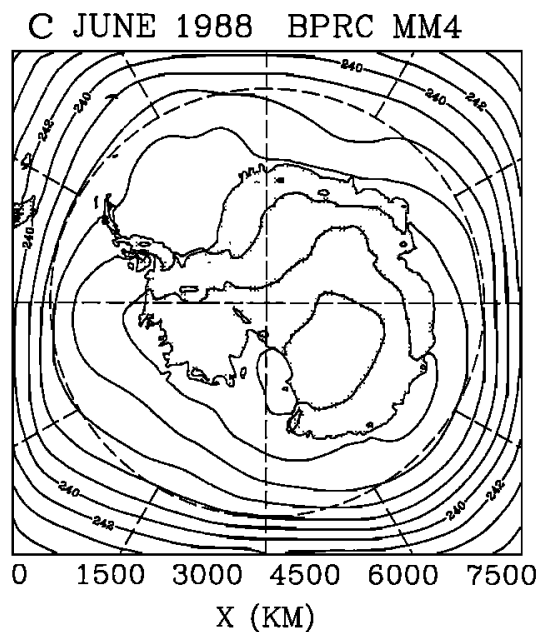

Figure 4. Same as Figure 2 except for temperature (degrees Kelvin) at $500 \mathrm{hPa}$. Contour interval is $2 \mathrm{~K}$. 

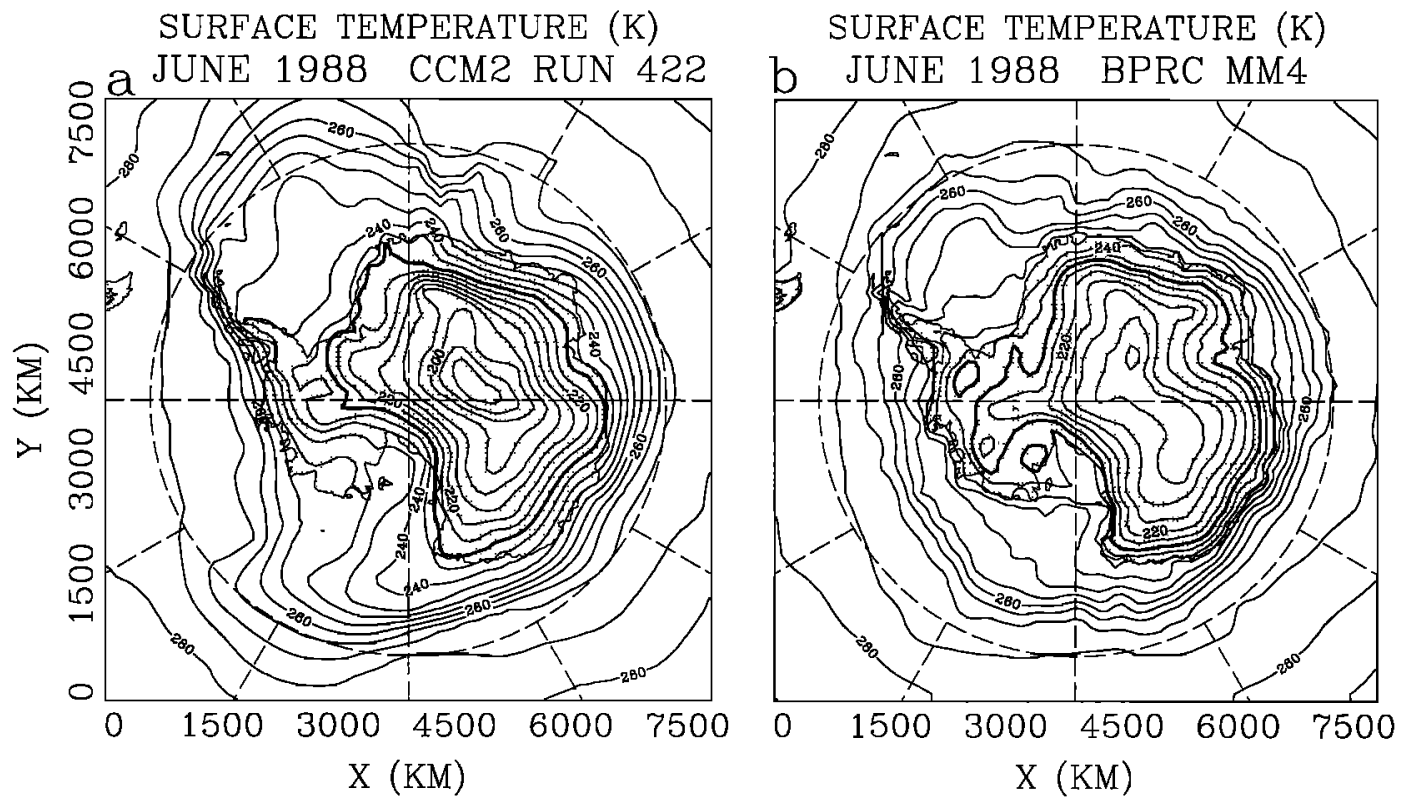

Figure 5. Surface temperature (degrees Kelvin) averaged over June 1988 for (a) CCM2 run 422 and (b) the dry MM4 simulation with CCM2 boundary conditions. Contour interval is $5 \mathrm{~K}$. Thick contour is $230 \mathrm{~K}$.

contribute to the differences in surface temperature between $0^{\circ}$ and $30^{\circ} \mathrm{E}$. Here, the PBL wind field is largely offshore in the CCM2 results, while the corresponding winds field in the MM4 results has a larger alongshore component, with anticyclonic turning offshore. Furthermore, significant differences between the models are seen in the oceanic surface temperature north of both the Ross Sea and the Weddell Sea where the CCM2 inversion intensity exceeds 10 $\mathrm{K}$ and $15 \mathrm{~K}$, respectively, while that of the mesoscale model is less than $2 \mathrm{~K}$. An evaluation of the models' physics suggests that $\mathrm{CCM} 2$ produces colder surface temperature than that of MM4 over the plateau due to the global model's smaller heat flux toward the Earth's surface from both the atmosphere and the subsurface. Furthermore, different treatments and distributions of sea ice by the two models contribute to dissimilar patterns of the sensible heat flux (not shown) over the Southern Ocean. In particular, the mixed ice/ocean grid points in MM4 allow larger heat flux to the relatively cold atmosphere than do the uniform $2 \mathrm{~m}$ thick sea ice grid points in CCM2.

The cold bias in the CCM2 results, for which the sea ice treatment is a contributing factor, could be associated with the improper positioning of the longwave trough over the Atlantic Ocean (Figures $2 b$ and $3 b$ ). An analysis of the daily output fields reveals that a significant blocking event occurs in the MM4 simulation beginning about June 13 and continuing to at least June 20. The bottom panels of Figure 7 displays MM4's $500 \mathrm{hPa}$ height field at an early stage, 0000

\section{LOWEST-LEVEL VELOCITY}

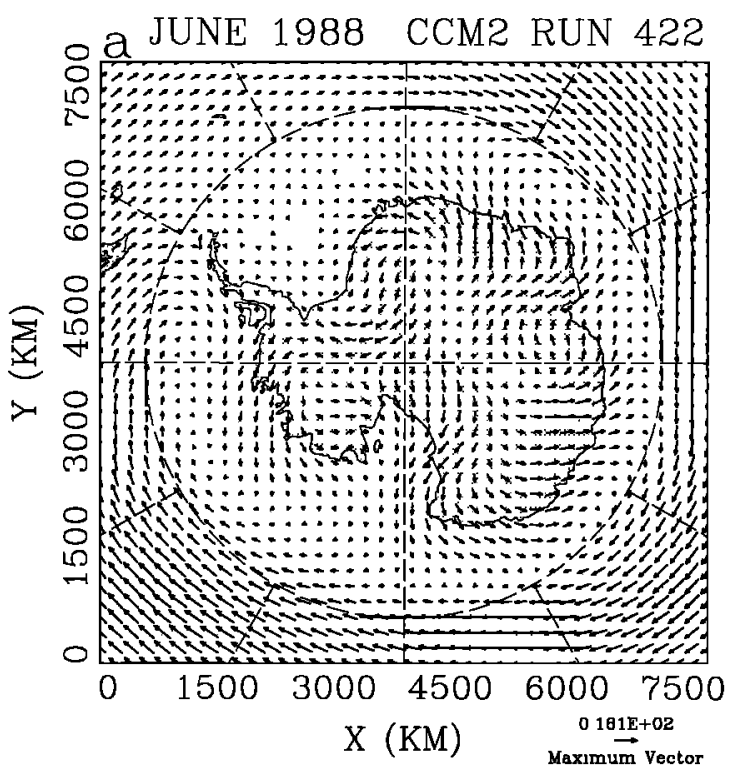

\section{LOWEST-LEVEL VELOCITY}
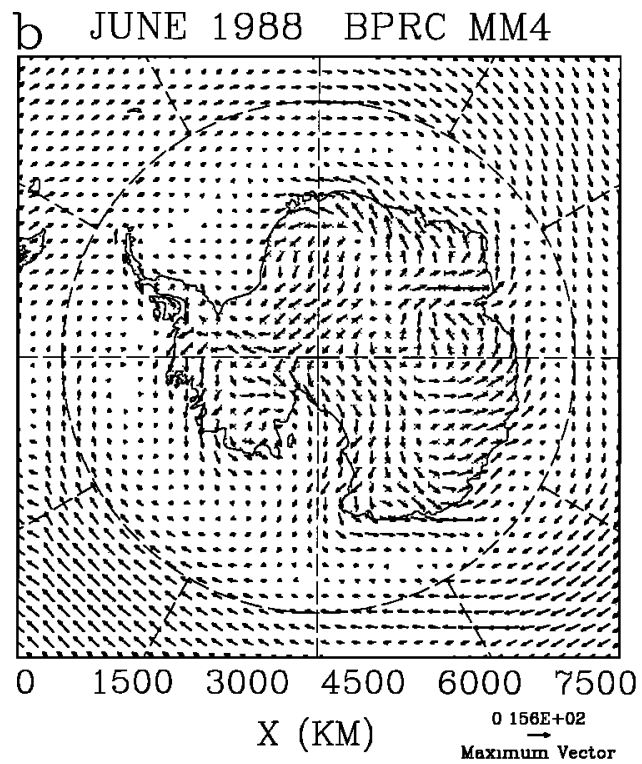

Figure 6. Same as Figure 5 except for lowest-level wind field (arrows). 

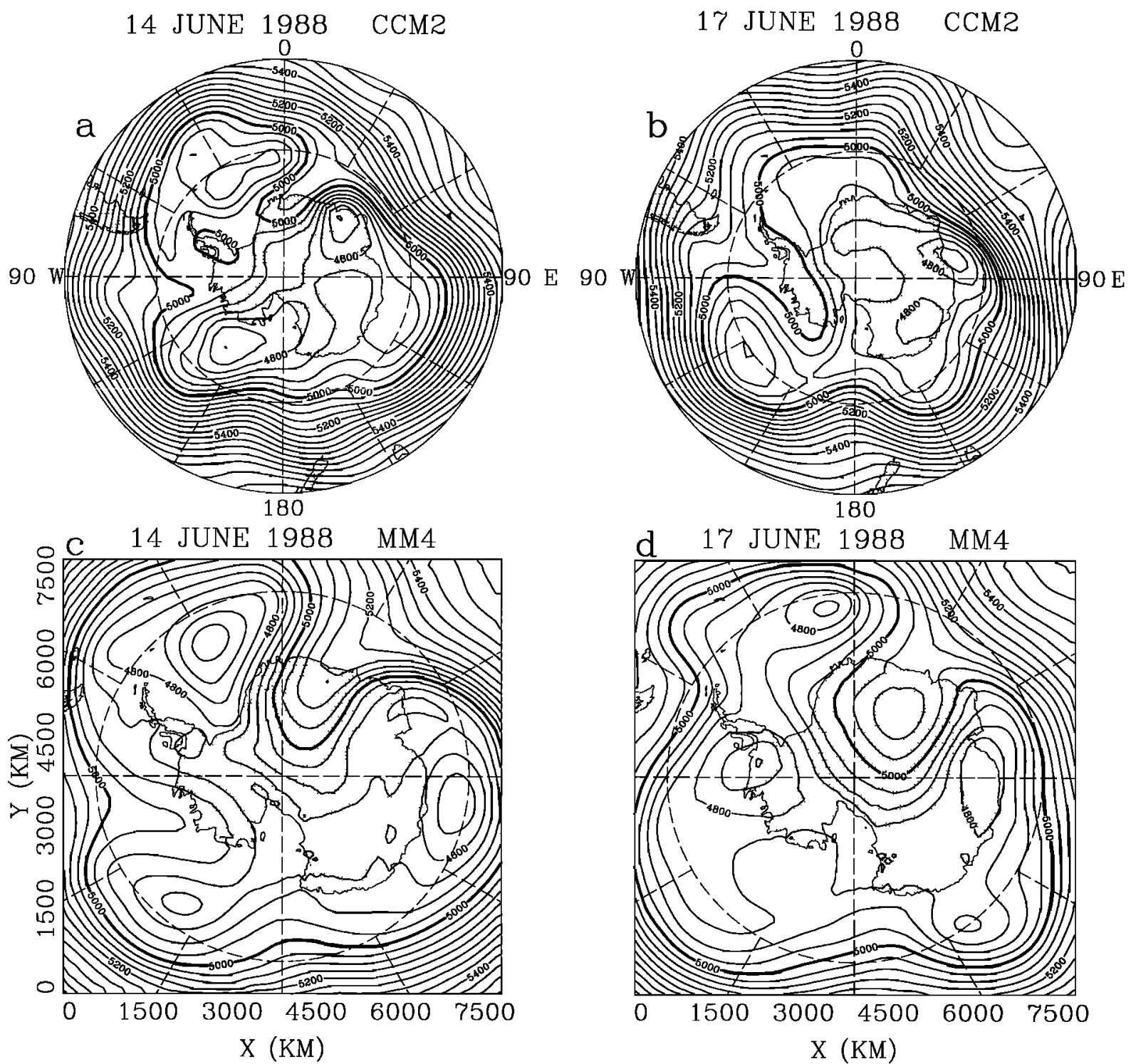

Figure 7. Geopotential height (geopotential meters) at $500 \mathrm{hPa}$ for (a) CCM2 run 422 at 0000 UTC June 14, 1988; (b) CCM2 run 422 at 0000 UTC June 17, 1988; (c) the dry MM4 simulation at 0000 UTC June 14, 1988; and (d) the dry MM4 simulation at 0000 UTC June 17, 1988. Contour interval is $50 \mathrm{gpm}$.

UTC June 14, and a mature stage, 0000 UTC June 17, of the blocking. The top panels display the corresponding fields from $\mathrm{CCM} 2$ run 422 . Only a weak ridge is seen near $5^{\circ} \mathrm{E}$ in Figure $7 \mathrm{a}$, and this ridge quickly dissipates. On the other hand, in the CCM2 simulation a ridge develops by 0000 UTC June 17 to the west of the Antarctic Peninsula, while in the MM4 simulation, the ridge near this region is weak or nonexistent to the south of the peninsula's northern tip. It is likely that the unequal resolution of the peninsula contributes to the model differences in this region. In the CCM2 simulations the development of a blocking ridge over East Antarctica, however, may be inhibited by the cold, strong vortex in the model climatology [Tzeng et al., 1994]. The relatively warmer conditions over the East Antarctic Plateau in MM4 simulations appear to be more favorable to ridging (HBP). Thus the blocking ridge seen in Figures $7 \mathrm{c}$ and $7 \mathrm{~d}$ should not be considered an anomalous event which biases the monthly mean but rather as an event representative of the model climatology. An effect of the block is that the low to the northwest must propagate to the east at a much slower rate than a corresponding low in CCM2 run 422. The duration of the block implies a significant effect on the location of the time-average trough located at $5^{\circ} \mathrm{W}$ in Figure $3 \mathrm{c}$.

The highly persistent katabatic winds can be seen in the lowest-level wind field displayed in Figure 6. Both CCM2 and MM4 simulate quite similar speed and direction in the drainage patterns. The mesoscale model with $100 \mathrm{~km}$ resolution does capture, to some extent, the local drainage through the large glacial valleys along the Transantarctic Mountains to the west of the Ross Ice Shelf and Ross Sea. The east to west variation in the surface wind field over the Ross Ice Shelf is better represented by MM4 as a barrier flow of katabatic origin to the east of the Transantarctic Mountains [see Bromwich et al., 1994]. Over the oceans the differences in the low-level flow between the models are largely related to differences in the sea level pressure fields.

In summary, we find that several improvements in the simulated climate are introduced by the one-way nesting of 
the limited-area MM4 within the global CCM2. In particular, the large-scale atmospheric circulation over the eastern Atlantic Ocean is improved. It is inferred that the improvement is related to increased blocking allowed by the warmer, more realistic temperatures over the East Antarctic Plateau. A good representation of the large-scale fields is almost certainly required at the horizontal boundaries for the mesoscale model to simulate the climate properly. Thus the MM4 simulation with boundary conditions adapted from CCM2 does not improve the poorly located atmospheric troughs over the Indian and Pacific Oceans. On the other hand, it has been shown by HBP that the troughs are properly located by the mesoscale model when the boundary conditions are well represented. Furthermore, the dry version of the mesoscale model reduces the cold bias seen in CCM2 results for the troposphere over Antarctica. The higher resolution also allows for more detail in the continent-wide drainage flow within the PBL.

\subsection{Moist Physics MM4 Simulation With ECMWF Initial and Boundary Conditions}

An important goal for modeling studies of high southern latitudes is the proper treatment of moist physics as the hydrology of the Antarctic Ice Sheet is critical to the global water balance. Parameterizations of regional clouds and hydrology, however, are hindered by inadequate observations. Existing physical parameterizations are often designed for tropical and midlatitude regions. To understand the effects of the mesoscale model's moist physics on simulations of the regional climate, we begin with a simulation that resembles the dry MM4 run of June 1988 by HBP. This new simulation, however, includes parameterizations for cloud physics, precipitation, and cloudradiation effects. For initial and boundary conditions, ECMWF analyses are used. The new simulation with the explicit moisture scheme appears to be an improvement over the dry simulation for grid points over the Southern Ocean. Over Antarctica, however, there are serious deficiencies in the moist physics simulation. Figure $8 \mathrm{a}$ displays the time- averaged sea level pressure field for the moist physics simulation for June 1988. The difference in sea level pressure between this simulation and that of the dry physics simulation of the same time period is shown in Figure 8b. The difference in sea level pressure between the moist simulation and that of the ECMWF analyses is shown in Figure 8c. Over the oceans the moist physics simulation produces significantly deeper minima in sea level pressure than the corresponding dry simulation. The simulated lows near $5^{\circ} \mathrm{W}$ and $80^{\circ} \mathrm{E}$ agree reasonably well with those analyzed by ECMWF (Figure 2a). The intensity of the circumpolar trough is also in good agreement with that of the ECMWF analyses, except offshore from West Antarctica, where the simulated sea level pressure is too low. Over the Amundsen Sea the sea level pressure difference between the moist and the dry simulations is as large as $16 \mathrm{hPa}$. There are some noticeable errors in the treatment of the double low in the South Pacific, yet the intensity of this feature is approximately captured. East of the Antarctic Peninsula the climatological ridge is not well captured, because the simulated sea level pressure underestimates the ECMWF analyzed sea level pressure by as much as $10 \mathrm{hPa}$.

The $500 \mathrm{hPa}$ geopotential height field produced by the moist physics simulation is shown in Figure 9a. Simulated heights are higher than analyzed heights over most of the domain (see Figure 9c). Lower than analyzed heights are located over portions of the South Pacific, especially near the Amundsen Sea. The height anomaly is especially large, typically 100 to $170 \mathrm{gpm}$, over the high plateau. Higher than analyzed temperature (by 3-5 K) contributes to the relatively large heights simulated over the plateau (Figure 10). The moist physics simulation produces anomalously cold temperatures near the Amundsen Sea. Figure 11 shows that over most of Antarctica, surface temperatures are substantially increased in the moist physics simulations above the reasonable values in the dry simulation of HBP. The minimum surface temperature is now just below $220 \mathrm{~K}$ over the plateau. Over the Ross Ice Shelf, temperatures are fairly uniform and unrealistically warm at approximately $253 \mathrm{~K}$.
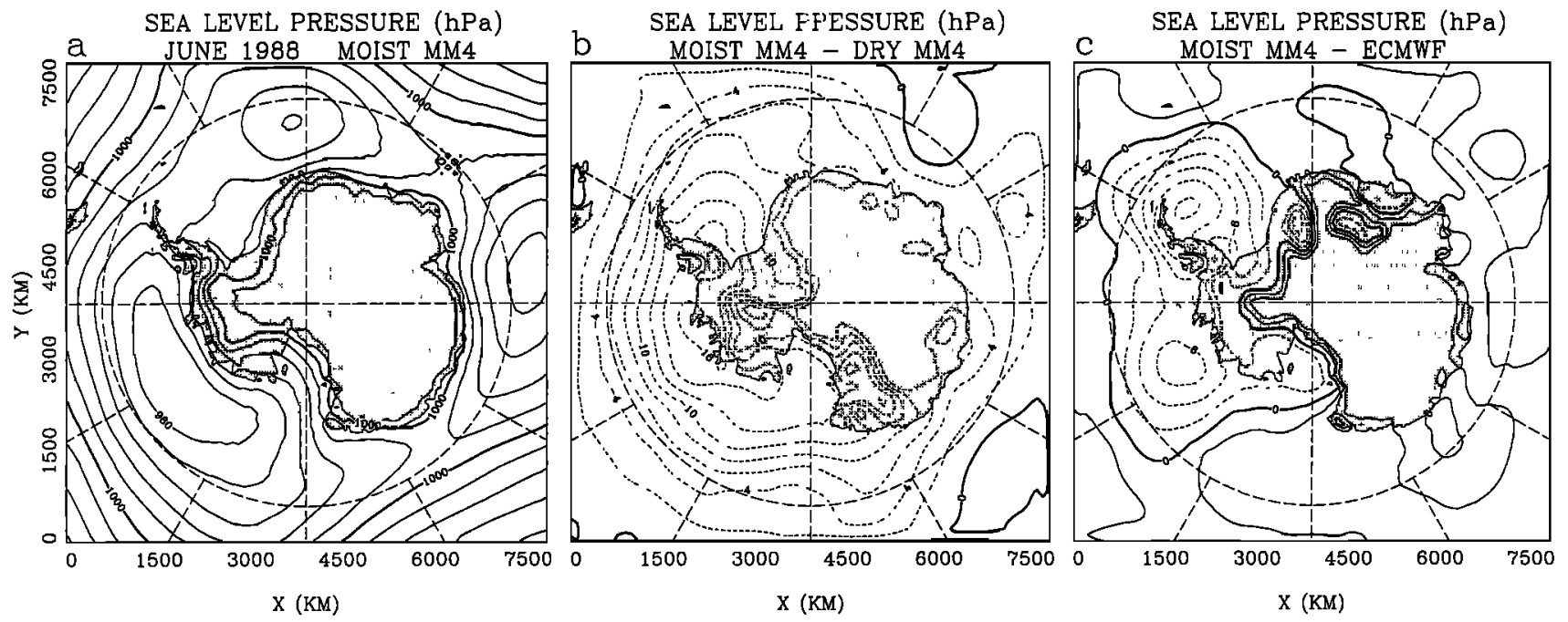

Figure 8. Sea level pressure (hectopascals) averaged over June 1988 for (a) the moist MM4 simulation, (b) moist MM4 simulation-dry MM4 simulation, and (c) moist MM4 simulation-ECMWF analyses. Contour interval is $4 \mathrm{hPa}$ for Figure $8 \mathrm{a}$ and $2 \mathrm{hPa}$ for Figures $8 \mathrm{~b}$ and $8 \mathrm{c}$. Negative contours are dashed. Thick contours are 0 and $1000 \mathrm{hPa}$. Contours are suppressed over high terrain. 

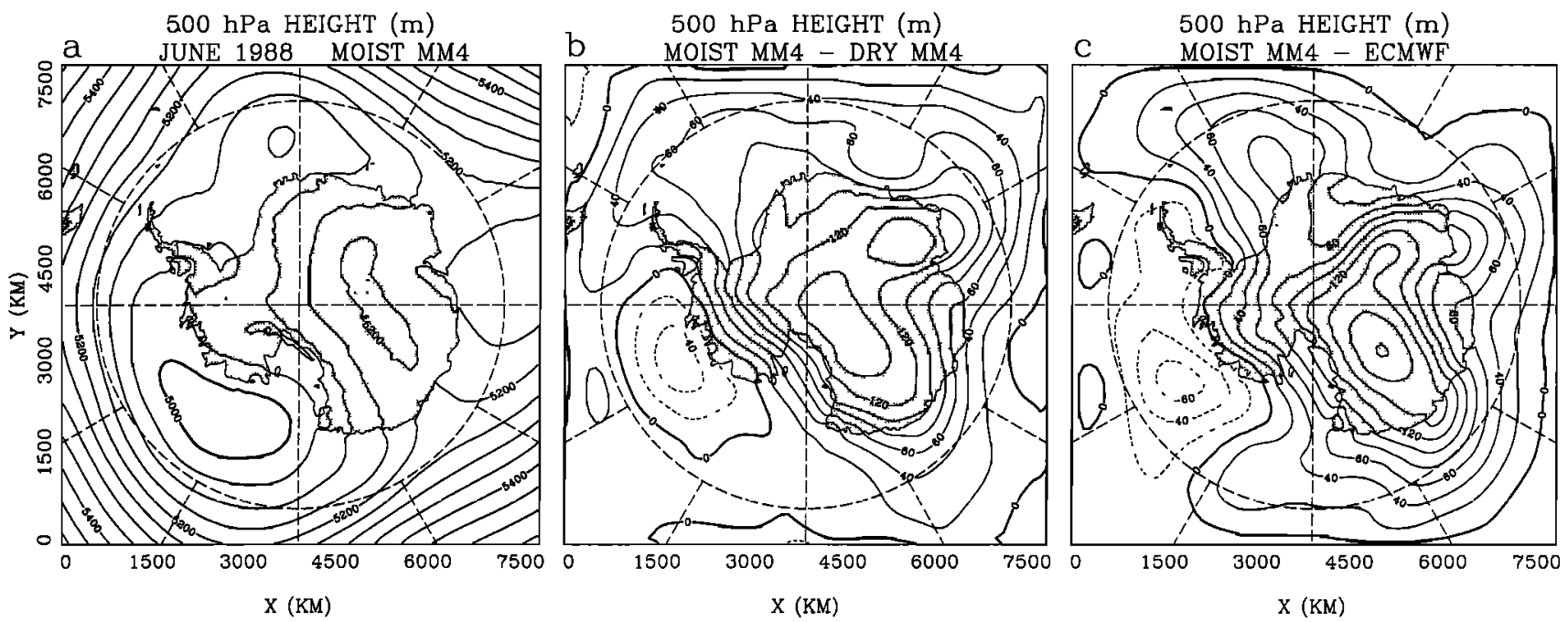

Figure 9. Same as Figure 8 except for geopotential height (geopotential meters) at $500 \mathrm{hPa}$. Contour interval is (a) $50 \mathrm{gpm}$ and (b) and (c) $20 \mathrm{gpm}$. Thick contours are 0 and $5000 \mathrm{gpm}$.

The simulated climate over Antarctica is therefore spurious in the moist physics simulation. Significant revision of the moist physics parameterization will be required before this version of the model can be used to realistically study the climate over Antarctica.

The introduction of moist physics raises the $500 \mathrm{hPa}$ geopotential heights over the majority of the high southern latitude domain (Figure 9b). The difference in height between the moist physics simulation and the dry simulation is as much as $150 \mathrm{gpm}$ over the plateau and $40-80 \mathrm{gpm}$ along the Indian and South Atlantic coasts. The height increases are accompanied by a warming of $3-5 \mathrm{~K}$ at $500 \mathrm{hPa}$ over Antarctica. Thus it appears that latent heating and cloud radiative effects lead to a significant warming in the simulation. With the strong Antarctic inversion and often large atmosphere to surface heat flux (HBP), upward longwave radiation at the surface should be significantly larger than the downward longwave radiation. This is the case for the dry simulations discussed by HBP; the upward radiation exceeds the downward radiation by $50.2 \mathrm{~W} \mathrm{~m}^{-2}$. For the moist physics simulation on the other hand, the incoming and outgoing longwave radiation, both $149 \mathrm{~W} \mathrm{~m}^{-2}$ at the surface, are balanced.

The total simulated precipitation for June 1988 is shown in Figure 12. Over the Southern Ocean, local monthly precipitation amounts of $5-10 \mathrm{~cm}$ are common. Typical precipitation amounts elsewhere are $1 \mathrm{~cm}$ for inland West Antarctica, $3 \mathrm{~cm}$ for the coastal Antarctica and 0.2 to $0.5 \mathrm{~cm}$ for the high East Antarctic Plateau. Despite the inadequate representation of geopotential height and temperature fields over Antarctica the forecasted precipitation appears to have a reasonable spatial distribution in Figure 12. According to Walsh and McGregor [1996] we can compare the simulated precipitation minus evaporation (PME) against that analyzed from meteorological analyses. Figure 13 shows the zonal average PME in centimeters for June 1988. Included in the figure is PME estimated by Bromwich et al. [1995b] from moisture flux convergence in the ECMWF analyses with the neglect of the storage term, which is small over long time scales. For the latitude band from $65^{\circ} \mathrm{S}$ to $70^{\circ} \mathrm{S}$, largely over
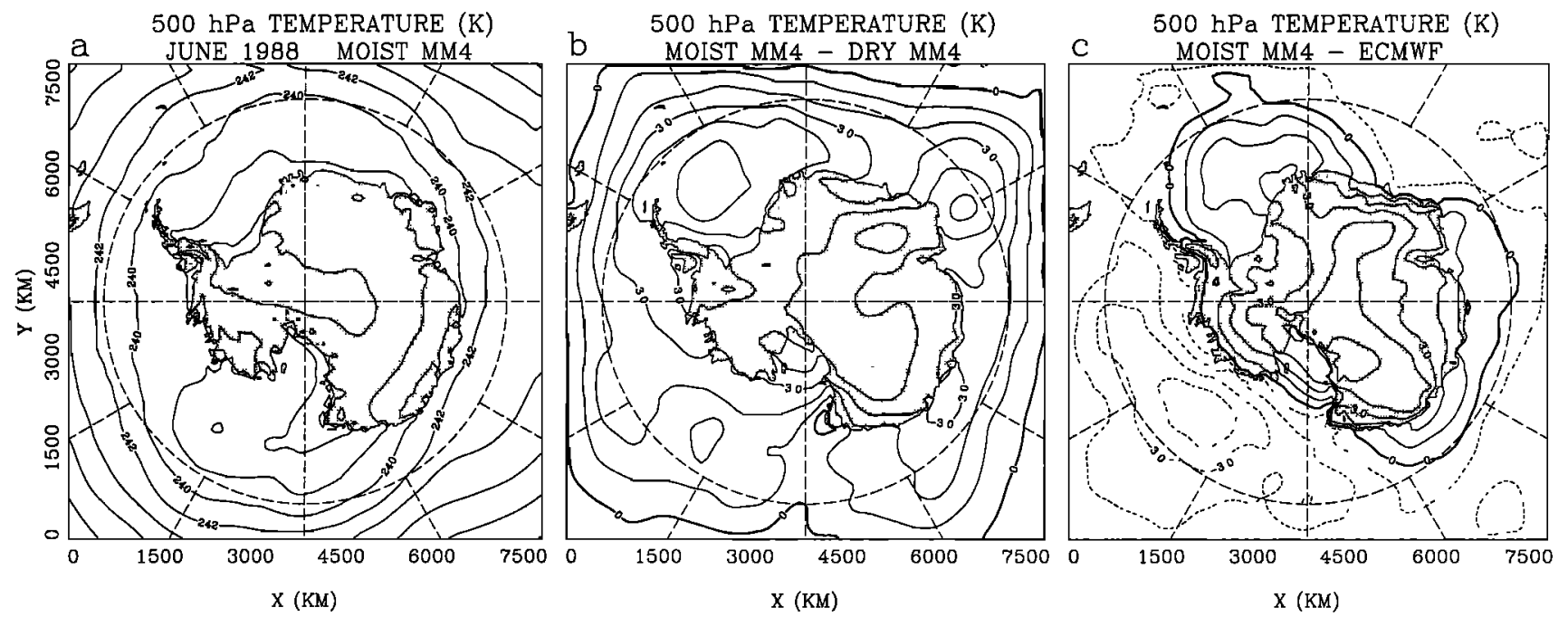

Figure 10. Same as Figure 8 except for temperature (degrees Kelvin) at $500 \mathrm{hPa}$. Contour interval is (a) $2 \mathrm{~K}$ and (b) and (c) $1 \mathrm{~K}$. The thick contour is $0 \mathrm{~K}$. 

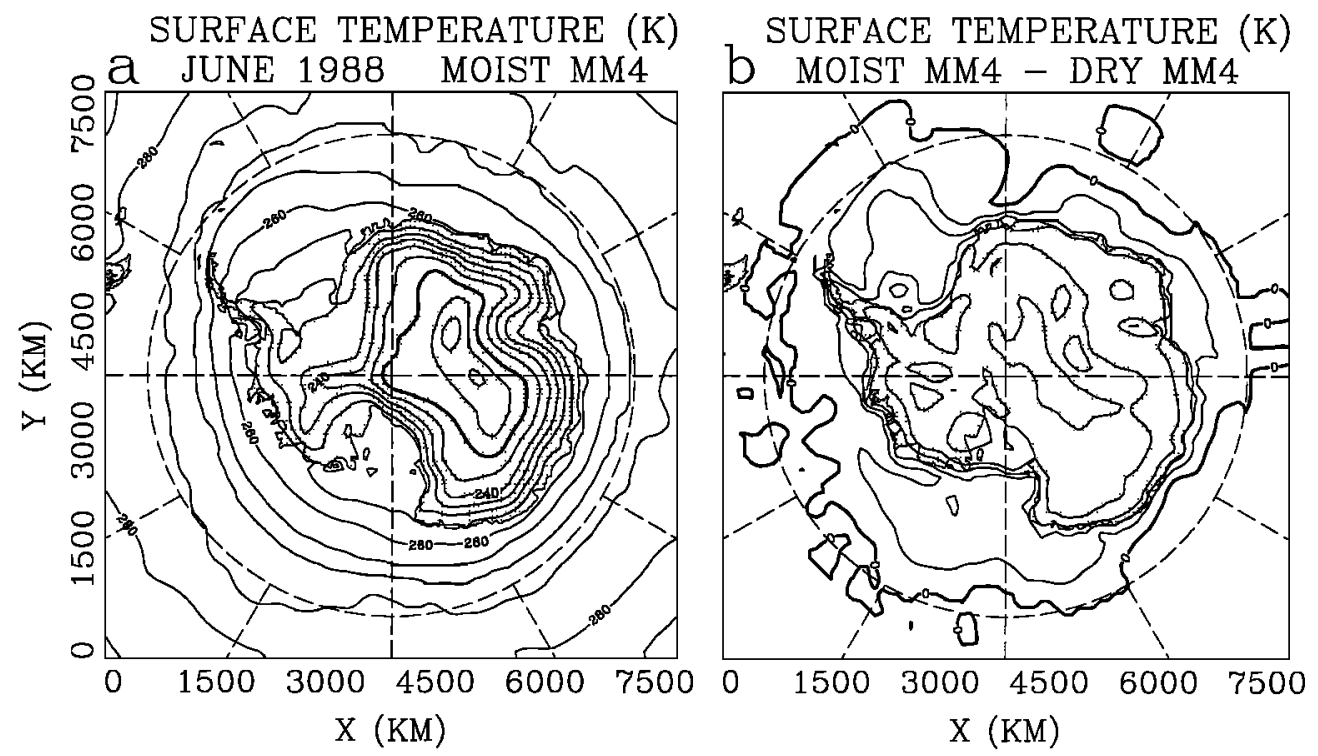

Figure. 11 Surface Temperature (degrees Kelvin) averaged for June 1988 for (a) the moist MM4 simulation and (b) difference moist MM4 simulation-dry MM4 simulation. Contour interval is (a) $5 \mathrm{~K}$ and (b) $2 \mathrm{~K}$. Thick contours are 0 and $230 \mathrm{~K}$.

the Southern Ocean, PME is about $3 \mathrm{~cm} \mathrm{month}^{-1}$ for both the model and that derived from the analyses. Mainly over Antarctica, from $70^{\circ} \mathrm{S}$ to $80^{\circ} \mathrm{S}$, model forecast PME is about 0.2 to $0.5 \mathrm{~cm}^{\text {month }}{ }^{-1}$ larger than the ECMWF analysesderived value. Nevertheless, the forecast PME appears quite reasonable, except for the high inland region from about $78^{\circ} \mathrm{S}$ to the south pole. For the high interior the forecast PME is roughly double the values derived from the analyses. Simulated evaporation, also shown in Figure 13, is relatively small south of $70^{\circ} \mathrm{S}$. Reasonable forecasts of precipitation in high southern latitude can be expected if the moisture flux is well represented by the model.

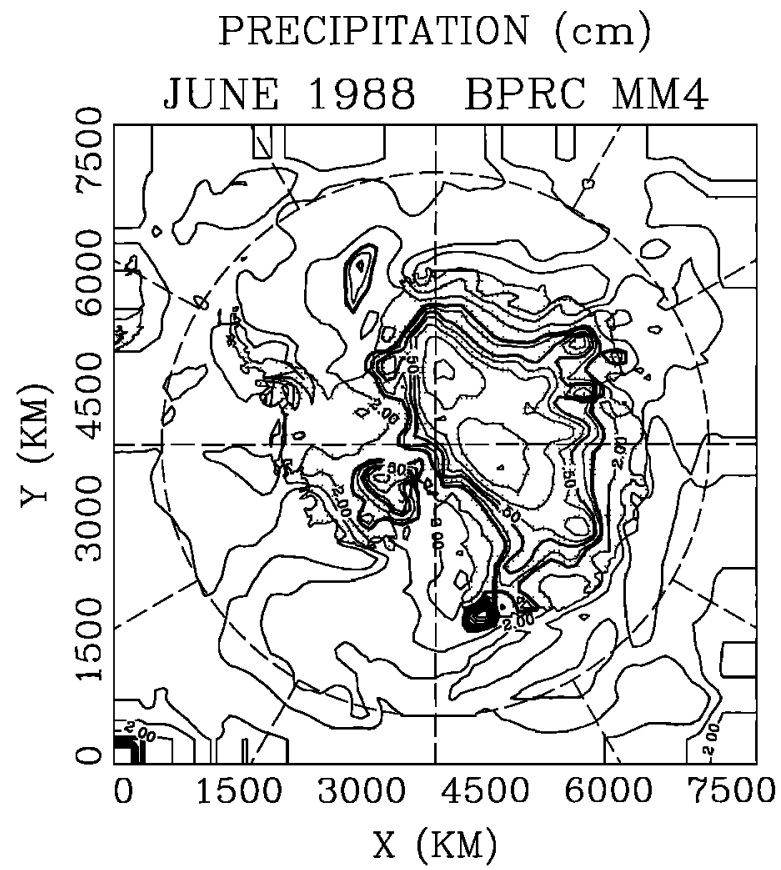

Figure 12. Monthly precipitation (centimeters) for the June 1988 moist MM4 simulation. Contours are $0.3,0.4,0.5,0.6$, $0.8,1.0,2.0,4.0$, and $6.0 \mathrm{~cm}$. Thick contour is $1.0 \mathrm{~cm}$.
Figure 14 displays zonally averaged, meridional moisture flux. Both the flux derived from the ECMWF analyses [Bromwich et al., 1995b] and that of MM4 show similar patterns over high southern latitudes. Over the Southern Ocean, the MM4 moisture flux has a magnitude about $10 \%$ to $15 \%$ larger than that of the analyses, so it is not surprising that the net accumulation over Antarctica is larger in the model results. The reasonable agreement between the magnitudes of the fluxes suggests that MM4 is treating well the high southern latitude cyclones that are responsible for the majority of the moisture flux. Nevertheless, treatment of the simulated clouds appears to be inadequate. Figure 15 displays zonally averaged, integrated water vapor and cloud mass in centimeters of liquid water equivalent depth. North of $75^{\circ} \mathrm{S}$, the MM4 vertically integrated water vapor is slightly larger, by $\sim 0.05 \mathrm{~cm}$, than that of the ECMWF analyses. Over interior Antarctica, water vapor is excessive in the model results, because simulated water vapor mass is roughly double that of the analyses for latitudes south of $75^{\circ} \mathrm{S}$. Relatively warm temperature and high relative humidity in the model results appear to be associated with the excessive water vapor. Figure 15 also shows that over the Southern Ocean, cloud mass is small compared to the water vapor mass. Near the south pole, however, cloud mass is the same order of magnitude as the water vapor mass. Clouds are apparently poorly treated by the model because the maximum cloud mass is not located in the relatively warm northern sections of the grid as anticipated. Rather, the maximum is located over inland Antarctica, near the south pole. Hines et al. (1997) find that the excess cloud mass is particularly evident in the upper troposphere, where values are at least an order of magnitude too large. They discuss inadequate autoconversion of cloud ice to precipitation as an important contributor to the difficulties. Obviously, the longwave radiation from these poorly treated clouds contributes to the warm bias over Antarctica in the MM4 results. In summary, for the winter simulation driven by boundary conditions adapted from ECMWF analyses, the addition of moist physics produces both beneficial effects, particularly over the Southern Ocean, and detrimental effects, particularly over Antarctica. 


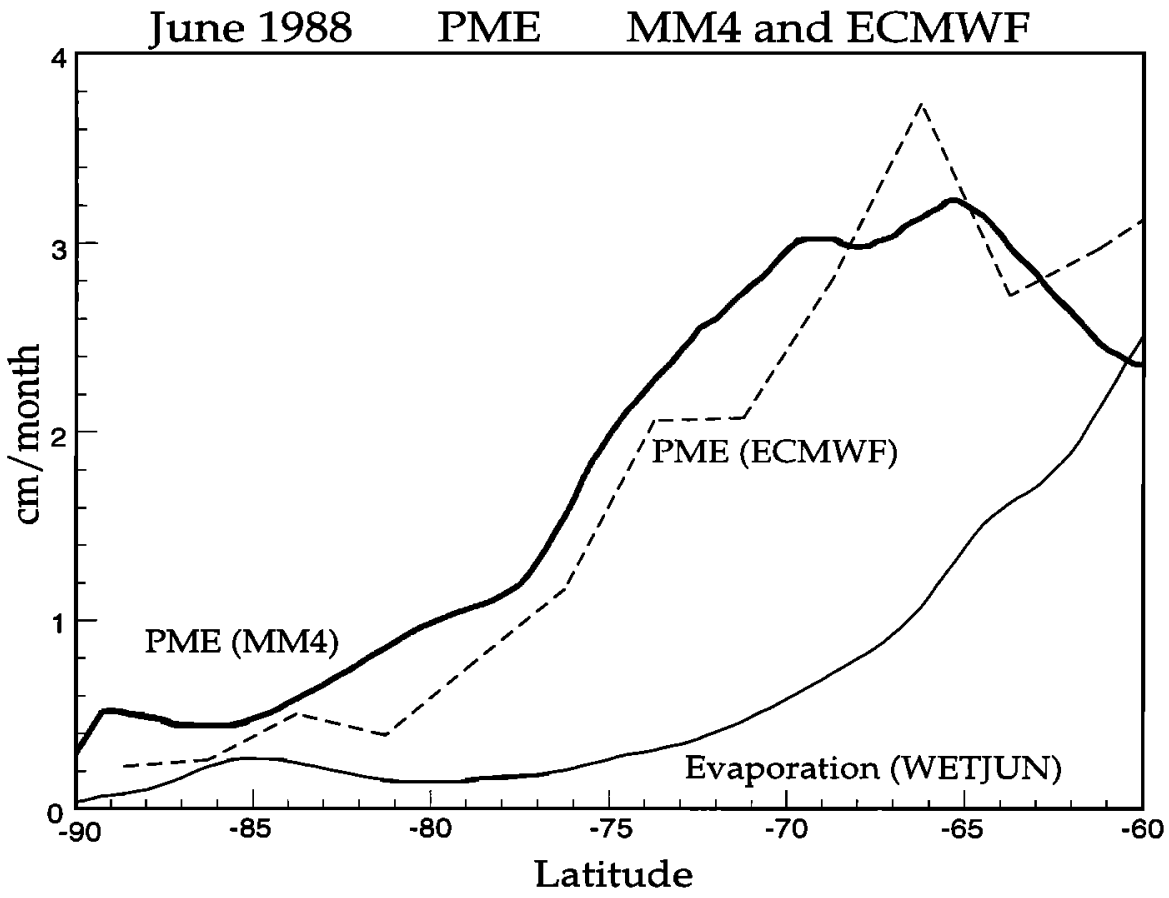

Figure 13. Zonally averaged precipitation-evaporation (centimeters per month) during June 1988 for the MM4 simulation (thick line), derived from the ECMWF analyses (dashed line) and zonally averaged MM4 evaporation (thin line, centimeters per month).

\subsection{Moist Physics MM4 Simulation With CCM2 Initial and Boundary Conditions}

An additional mesoscale simulation is performed with the combination of the one-way nesting inside CCM2 run 422 discussed in section 3.1 and the moist physics parameterization discussed in section 3.2. The results of the June 1988 simulation will be compared against the those of run 422. The effect of the moist physics in this nested simulation is very similar to the effects seen in the simulation with initial and boundary conditions drawn from ECMWF analyses. The time-average sea level pressure field, along with its difference fields from that of the dry nested run and CCM run 422 , is displayed in Figure 16 . Notice that the circumpolar trough in Figure $16 \mathrm{a}$ is not only deeper than that of the corresponding dry simulation (Figure 2c) but also slightly deeper than that of the intense trough in run 422 (Figure 2b). The sea level pressure in the circumpolar trough varies typically from 968 to $980 \mathrm{hPa}$. Over the oceans, latent heating is most probably responsible for the pressure reduction from that of the corresponding dry simulation. The

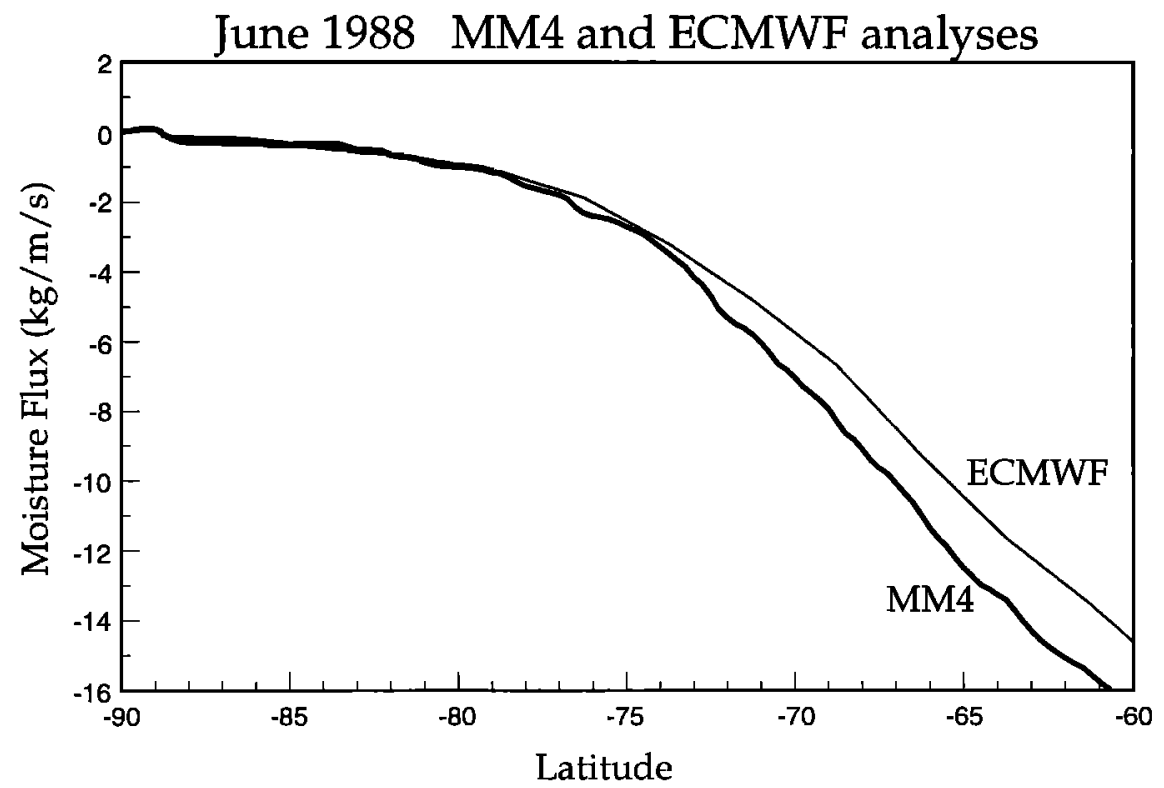

Figure 14. Zonally averaged meridional moisture flux (kilograms per meter per second) for the June 1988 MM4 simulation (thick line) and derived from the ECMWF analyses (thin line). Negative values are southward. 


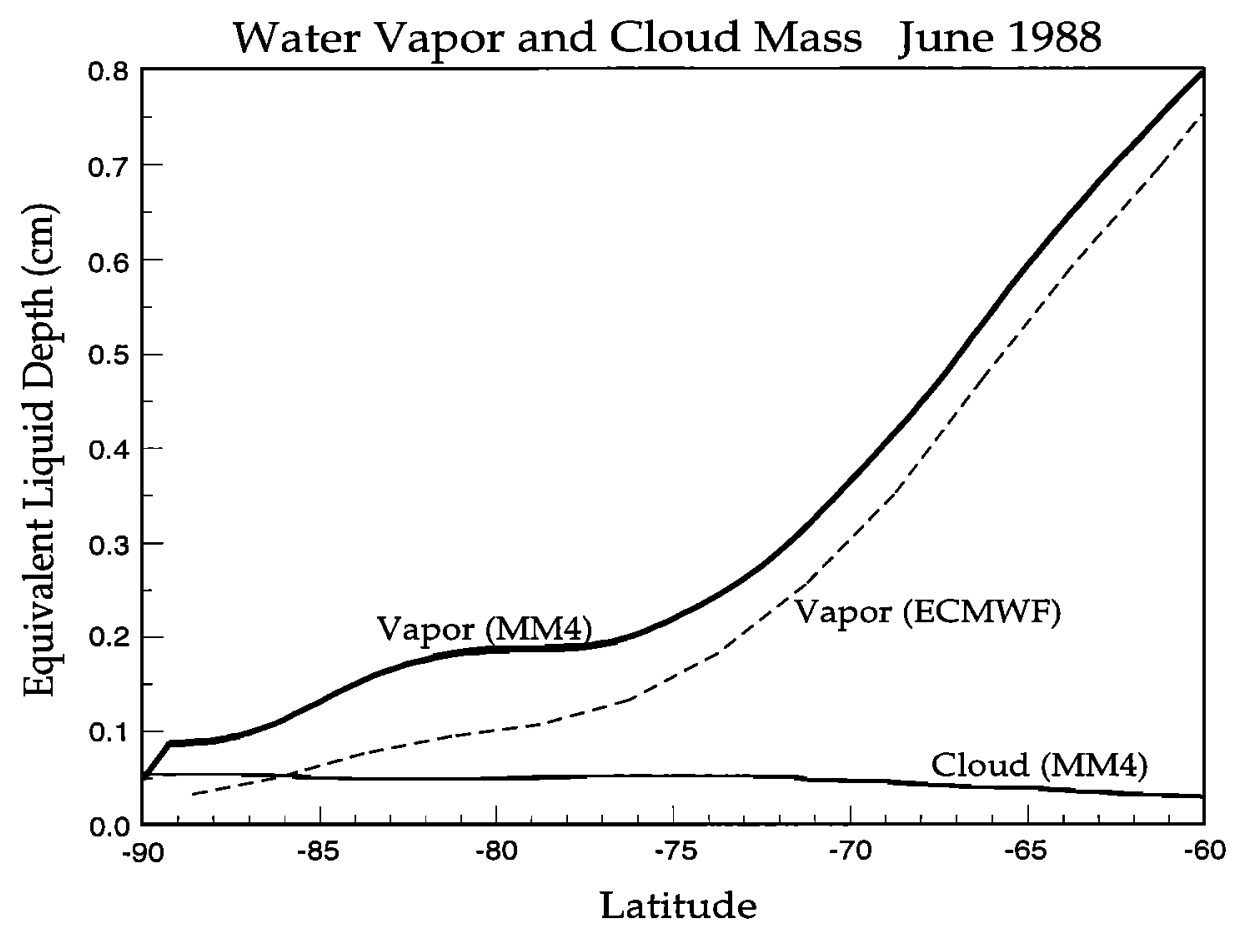

Figure 15. Liquid water equivalent depth (centimeters) of zonally averaged water vapor and cloud mass in a vertical column during June 1988 for the MM4 simulation (water vapor, thick line; cloud mass, thin line) and the ECMWF analyses (water vapor, dashed line).

trough over the Atlantic Ocean, which was well located in the dry simulation, is now centered near $30^{\circ} \mathrm{W}$, significantly farther to the west than that of the ECMWF analyses (Figure 2a). On the other hand, the double low feature over the Pacific Ocean is now well located by the mesoscale model. The minimum pressure is located near $150^{\circ} \mathrm{W}$, close to the Ross Sea, and close to the corresponding position in the ECMWF analyses. The sea level pressure, however, is up to $20 \mathrm{hPa}$ lower than that of the analyses in this region. It would appear that the nested higher-resolution model cannot correct for this bias in CCM2 output.
While the circumpolar trough is strengthened at the surface, the intensity of the circumpolar vortex in the middle troposphere is noticeably weakened in the moist physics simulation (Figure 17) with boundary conditions adapted from CCM2 run 422. Geopotential heights over Antarctica are increased over that of the corresponding dry run by typically 100 to $160 \mathrm{gpm}$. Nevertheless, the geopotential height over Antarctica is still considerably less than that of the ECMWF analyses but is up to $200 \mathrm{gpm}$ higher than that of the CCM2 run. The weaker vortex in Figure $17 \mathrm{a}$ is hydrostatically related to the 3 to $5 \mathrm{~K}$ higher temperatures
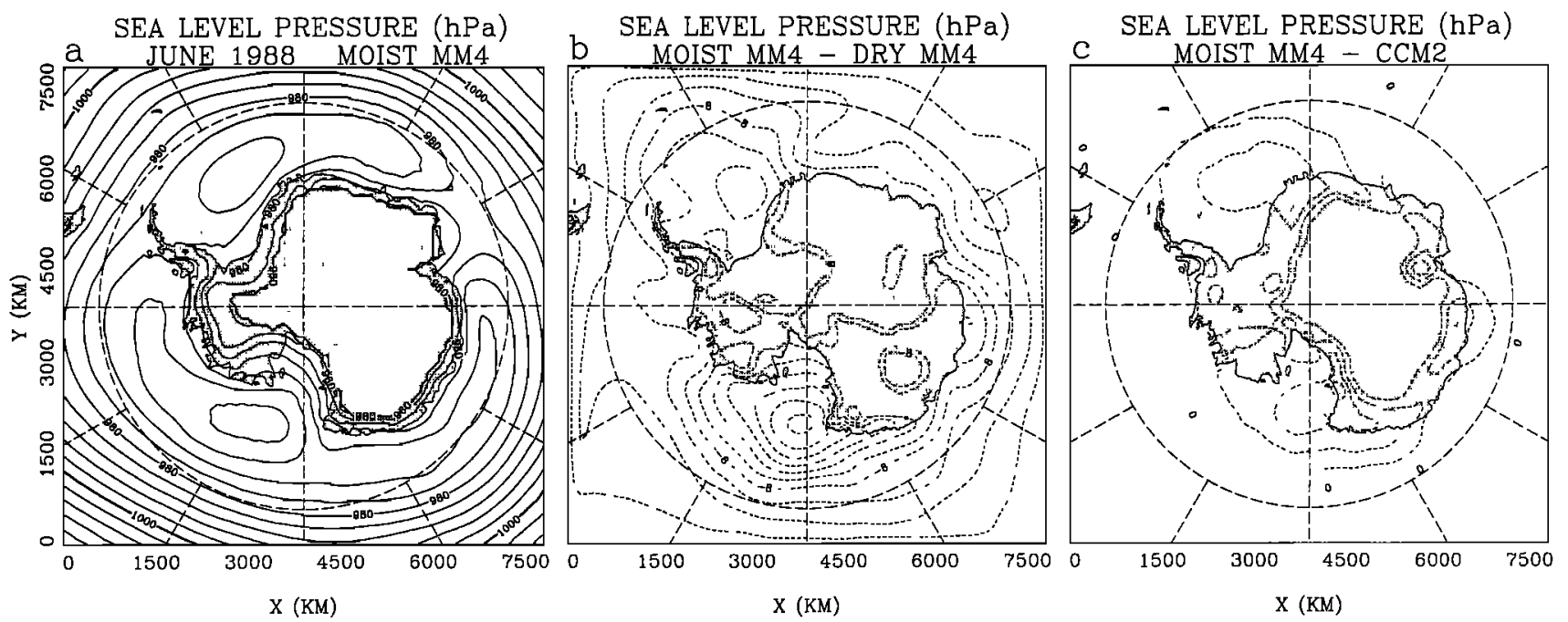

Figure 16. Sea level pressure (hectopascals) averaged over June 1988 for (a) the moist physics MM4 simulation with CCM2 initial and boundary conditions, (b) the difference in sea level pressure between the moist and the dry simulations with CCM2 initial and boundary conditions, and (c) the pressure difference between the moist physics simulation and the CCM2 simulation. Contour interval is (a) $4 \mathrm{hPa}$ and (b) and (c) $2 \mathrm{hPa}$. Thick contours are 0 and $1000 \mathrm{hPa}$. Contours are suppressed over high terrain. 

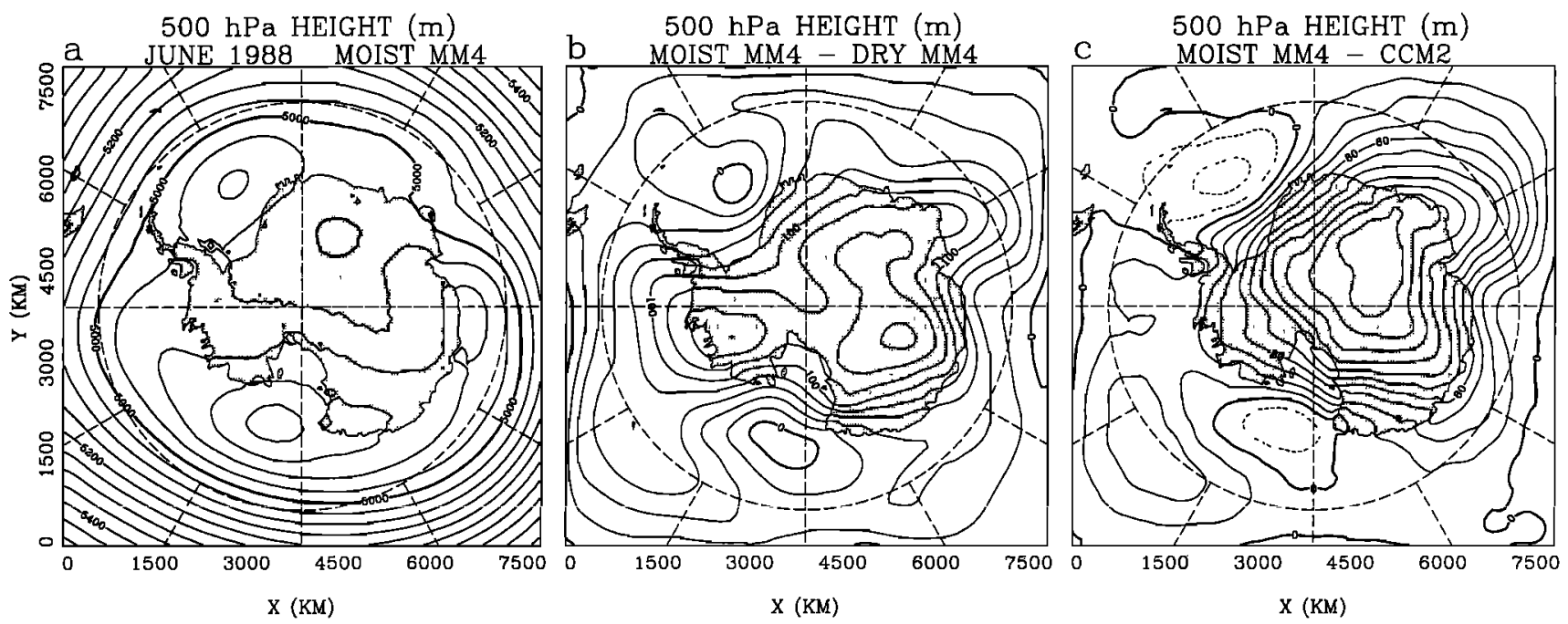

Figure 17. Same as Figure 16 except for $500 \mathrm{hPa}$ geopotential height (geopotential meters). Contour interval is (a) $50 \mathrm{gpm}$ and (b) and (c) $20 \mathrm{gpm}$. Thick contours are 0 and $5000 \mathrm{gpm}$.

(not shown) in the middle troposphere. The warming, apparently due to excessive back radiation from clouds, is quite large at the surface. Surface temperature (not shown) over the high East Antarctic Plateau is as much as $29 \mathrm{~K}$ warmer than that of CCM2 run 422. In summary, the impact of the moist physics in the one-way nested simulation is similar, for the most part, to that seen in the simulation driven by ECMWF boundary conditions. The moist physics has also had a significant influence on the location of the major longwave troughs at high southern latitudes.

\section{Discussion and Conclusions}

Simulations with a modified version of the MM4 mesoscale model examine the winter meteorology of high southern latitudes. This work is a continuation of the modeling studies of Hines et al. [1995]. They performed a cloud-free mesoscale simulation of June 1988 with initial and boundary conditions supplied by ECMWF analyses. Their model results agreed well with ECMWF analyses and AWS observations. The present study now includes simulations with the hydrologic cycle including precipitation, evaporation, latent heating and cloud radiation effects. Three simulations are performed. In the first simulation, the mesoscale model is run cloud-free for one winter month, June 1988 , with initial and boundary conditions supplied by the NCAR CCM2 global climate model. A comparison of the results of the nested mesoscale simulation against the regional results of CCM2 is performed. The comparison reveals that the nesting can result in substantially different meteorological fields, including improvements such as the relocation of a large-scale atmospheric trough over the Atlantic Ocean and a reduction in the cold bias over the interior of Antarctica. The more realistic positioning of the trough is related to a blocking event during the middle of the month. It is inferred that the noted development of the blocking ridge over the East Antarctic Plateau is favored by the relatively weak interior vortex in the MM4 results, while the stronger, colder vortex in the CCM2 results suppresses the ridge development. Even with these improvements, the improper positioning of the longwaves at the horizontal boundaries leads to errors in the positioning of the other large-scale waves in the MM4 results.

The second MM4 simulation includes forcing by boundary conditions from ECMWF analyses. The full hydrologic cycle is included in this simulation. Over most of the mesoscale domain, simulated precipitation and moisture fluxes agree well with values derived by Bromwich et al. [1995b] from ECMWF analyses. Over the interior of Antarctica the simulated PME, however, is about twice as large as that derived from the analyses. The excessive temperature simulated over Antarctica may contribute to the excessive precipitation. The explicit moisture physics package included within MM4 is very inadequate for Antarctica. Over the surrounding ocean, however, the moist physics results in an improved sea level pressure pattern. In particular, the intensity of the circumpolar trough was well simulated. The problems over Antarctica probably arise from the conversion terms between vapor, cloud, and precipitation particles [Hines et al., 1997]. It also appears that excessive moisture is stored in Antarctic clouds. The results of the present study emphasize the need for testing and development of physical parameterizations adapted especially for high southern latitudes, in particular, and for the polar regions in general.

The third simulation includes moist physics in a simulation driven by boundary conditions adapted from CCM2 output. The effect of latent heating on the simulations is similar to that observed in the moist physics simulation with ECMWF boundary conditions. The intensity of the circumpolar trough is increased in both moist physics simulations, probably because of the latent heat released by migrating cyclones. Over the interior of Antarctica the moist physics produces substantially increased temperature at the surface and higher up in the troposphere. Overall, we find that nesting a mesoscale model (MM4) within a GCM (CCM2) can improve the simulation of a regional climate as well as providing a higher-resolution depiction of a regional climate. The dry version of the mesoscale model provides a good basic depiction of the climate over Antarctica during winter. Attempts to improve upon the simulation of high southern latitude climate are limited by the inadequacy of the treatment of moist physics processes. 
Acknowledgments. This research is supported by a fellowship of the University Corporation for Atmospheric Research Climate System Modeling Program and by NASA via grant NAGW-2718 to the second author. Derived moisture fluxes and PME were provided by Richard Cullather of the Byrd Polar Research Center. The numerical model was provided by Thomas Parish at the University of Wyoming, and the radiation code was provided by Ruby Leung at the Pacific Northwest Laboratory. The numerical simulations were performed on the CRAY Y-MP at the Ohio Supercomputer Center, which is supported by the State of Ohio, and on the CRAY Y-MP at NCAR, which is supported by the National Science Foundation. This is contribution 1016 of Byrd Polar Research Center.

\section{References}

Anthes, R. A., E.-Y. Hsie, and Y.-H. Kuo, Description of the Penn State/NCAR mesoscale model version 4 (MM4), NCAR Tech. Note, NCAR/TN-282+STR, 66 pp., Natl. Cent. for Atmos. Research, Boulder, Colo., 1987.

Bromwich, D. H., B. Chen, and R.-Y. Tzeng, Arctic and Antarctic precipitation simulations produced by the NCAR Community Climate Models, Ann. Glaciol., 21, 117-122, 1995a.

Bromwich, D. H., F. M. Robasky, R. I. Cullather, and M. L. Van Woert, The atmospheric hydrologic cycle over the Southern Ocean and Antarctica from operational numerical analyses, Mon. Weather Rev., I23, 3518-3538, 1995b.

Bromwich, D. H., Y. Du, and T. R. Parish, Numerical simulation of winter katabatic winds from West Antarctica crossing Siple Coast and the Ross Ice Shelf, Mon. Weather Rev., 122, 14171435, 1994.

Brost, R. A., and J. C. Wyngaard, A model study of the stablystratified planetary boundary layer, J. Atmos. Sci., 35, 14271440,1978 .

Cerni, T. A., and T. R. Parish, A radiative model of the stable noctumal boundary layer with application to the polar night, $J$. Clim. Appl. Meteorol., 23, 1563-1572, 1984.

Chen, B., D. H. Bromwich, K. M. Hines, and X. Pan, Simulations of the 1979-1988 polar climates by global climate models, Ann. of Glaciol., 21, 83-90, 1995.

Drewry, D. J., The surface of the Antarctic ice sheet, in Antarctica: Glaciological and Geophysical Folio, sheet 2, edited by D. J. Drewry, Scott Polar Res. Inst., Cambridge, UK, 1983.

Dudhia, J., Numerical study of convection observed during the winter monsoon experiment using a mesoscale two-dimensional model, J. Atmos. Sci., 46, 3077-3107, 1989.

Gallee, H., Simulation of the mesocyclonic activity in the Ross Sea, Antarctica, Mon. Weather Rev., 123, 2051-2069, 1995.

Gallée, H., and G. Schayes, Development of a three-dimensional meso- $\gamma$ primitive equation model: Katabatic winds simulation in the area of Terra Nova Bay, Antarctica, Mon. Weather Rev., 122, 671-685, 1994.

Gates, W. L., AMIP, The Atmospheric Model Intercomparison Project, Bull. Am. Meteorol. Soc., 73, 1962-1970, 1992.

Giorgi, F., and G. T. Bates, The climatological skill of a regional model over complex terrain, Mon. Weather Rev., 117, 2325$2347,1989$.

Giorgi, F., C. S. Brodeur, and G. T. Bates, Regional climate change scenarios over the United States produced with a nested regional climate model, J. Clim., 7, 375-399, 1994.

Hack, J. J., B. A. Boville, B. P. Briegleb, J. T. Kiehl, P. J. Rasch, and D. L. Williamson, Description of the NCAR Community Climate Model (CCM2), NCAR Tech. Note, NCAR/TN-382+STR, 108 pp., Natl. Cent. for Atmos. Res., Boulder, Colo., 1993.

Hines, K. M., D. H. Bromwich, and R. I. Cullather, Evaluating moist physics for Antarctic mesoscale simulations, Ann. Glaciol., 25, in press, 1997.

Hines, K. M., D. H. Bromwich, and T. R. Parish, A mesoscale modeling study of the atmospheric circulation of high southern latitudes, Mon. Weather Rev., 123, 1146-1165, 1995.

Hsie, E.-Y., and R. A. Anthes, Simulations of frontogenesis in a moist atmosphere using alternative parameterizations of condensation and precipitation, J. Atmos. Sci., 4I, 2701-2716, 1984.

Lynch, A. H., W. L. Chapman, J. E. Walsh, and G. Weller, Development of a regional climate model of the western Arctic, J. Clim., 8, 1555-1570, 1995.

Mather, K. B., and G. S. Miller, Notes on the topographic factors affecting the surface wind in Antarctica, with special reference to katabatic winds, and bibliography, Rep. UAG-189, Geophys. Inst., Univ. of Alaska, Fairbanks, 1967.

Moritz, R. E., J. A. Curry, A. S. Thorndike, and N. Untersteiner, SHEBA, a research program on the surface heat budget of the Arctic Ocean, 34 pp., ARCSS OAII Sci. Manage. Off., Seattle, Wash., 1993.

Parish, T. R., On the interaction between Antarctic katabatic winds and tropospheric motions in the high southern latitudes, Aust. Meteorol. Mag., 40, 149-167, 1992.

Parish, T. R., and D. H. Bromwich, Continental-scale simulation of the Antarctic katabatic wind regime, J. Clim., 4, 135-146, 1991.

Parish, T. R., and K. T. Waight, The forcing of Antarctic katabatic winds, Mon. Weather Rev., 115, 2214-2226, 1987.

Peixoto, J. P., and A. H. Oort, Physics of Climate, 520 pp., Am. Inst. of Phys., New York, 1992.

Phillpot, H. R., and J. W. Zillman, The surface temperature inversion over the Antarctic continent, J. Geophys. Res., 75, 4161-4169, 1970.

Pitman, A. J., F. Giorgi, and A. Henderson-Sellers, Southeast Australia's wintertime precipitation: Sensitivity of climate predictions to model resolution, Aust. Meteorol. Mag., 39, 21-35, 1991.

Stearns, C. R., L. M. Keller, G. A. Weidner, and M. Sievers, Monthly mean climatic data for Antarctic automatic weather stations. in Antarctic Meteorology and Climatology: Studies Based on Automatic Weather Stations, Antarct, Res. Ser.. vol. 61, edited by D. H. Bromwich and C. R. Stearns, pp. 1-21, AGU, Washington, D.C., 1993.

Tzeng, R.-Y., D. H. Bromwich, and T. R. Parish, Present-day Antarctic climatology of the NCAR Community Climate Model Version 1, J. Clim., 6, 205-226, 1993.

Tzeng, R.-Y., D. H. Bromwich, T. R. Parish, and B. Chen, NCAR CCM2 simulation of the modern Antarctic climate, J. Geophys. Res., 99, 23,131-23,148, 1994.

Walsh, K., and J. L. McGregor, Simulations of Antarctic climate using a limited area model, J. Geophys. Res., 101, 19,093$19,108,1996$

Williamson, G. S., CCM2 data sets and circulation statistics, NCAR Tech. Note, NCAR/TN-39I+STR, 85 pp., Natl. Cent. for Atmos. Res., Boulder, Colo., 1993.

Williamson, D. L., J. T. Kiehl, V. Ramanathan, R. E. Dickinson, and J. J. Hack, Description of the NCAR Community Climate Model (CCM1), NCAR Tech. Note, NCAR/TN-285+STR, 112 pp., Natl. Cent. for Atmos. Res., Boulder, Colo., 1987.

$\mathrm{Xu}, \mathrm{J} .-\mathrm{S}$., H. von Storch, and H. van Loon, The performance of four spectral GCMs in the Southern Hemisphere: The January and July climatology and the semiannual wave, J. Clim., 3, 53-70, 1990.

Zhang, D.-L., and R. A. Anthes, A high-resolution model of the planetary boundary layer-sensitivity tests and comparisons with SESAME-79 data, J. Appl. Meteorol., 21, 1594-1609, 1982.

D. H. Bromwich, K. M. Hines, and Z. Liu, Byrd Polar Research Center, Ohio State University, 108 Scott Hall, 1090 Carmack Road, Columbus, OH 43210-1002.

(Received March 8, 1996; revised August 12, 1996; accepted March 12, 1997.) 